\title{
A Controlled Naturalistic Study on a Weekly Music Therapy and Activity Program on Disruptive and Depressive Behaviors in Dementia
}

\author{
Peimin Han ${ }^{a}$ Melanie Kwan ${ }^{b}$ Denise Chen ${ }^{a, b}$ Siti Zubaidah Yusoff ${ }^{a}$ \\ Hui Ling Chionh ${ }^{b}$ Jenny Goh ${ }^{d}$ Philip Yap ${ }^{\text {b, c }}$ \\ ${ }^{a}$ Rehabilitation Department, Occupational Therapy, ${ }^{b}$ Geriatric Centre, ${ }^{c}$ Department of Geriatric Medicine, and \\ ${ }^{\mathrm{d}}$ Department of Medical Social Service, Singapore
}

\section{Key Words}

Dementia $\cdot$ Music therapy $\cdot$ Occupational therapy $\cdot$ Quality of life $\cdot$ Depression $\cdot$ Behavior $\cdot$ Meaningful activity

\begin{abstract}
Aim: This study explores the effects of a weekly structured music therapy and activity program (MAP) on behavioral and depressive symptoms in persons with dementia (PWD) in a naturalistic setting. Methods: PWD attended a weekly group MAP conducted by a qualified music therapist and occupational therapist for 8 weeks. Two validated scales, the Apparent Emotion Scale (AES) and the Revised Memory and Behavioral Problems Checklist (RMBPC), were used to measure change in outcomes of mood and behavior. Results: Twenty-eight subjects completed the intervention, while 15 waitlist subjects served as controls. Baseline AES and RMBPC scores were not significantly different between the intervention and control groups. After intervention, RMBPC scores improved significantly $(p=0.006)$ with $95 \% \mathrm{Cl}$ of the difference between the mean intervention and control group scores compared to baseline at -62.1 to -11.20 . Total RMBPC scores in the intervention group improved from 75.3 to 54.5 , but worsened in the control group, increasing from 62.3 to 78.6. AES scores showed a nonsignificant trend towards im-
\end{abstract}

provement in the intervention group. Conclusion: The results suggest that a weekly MAP can ameliorate behavioral and depressive symptoms in PWD.

Copyright $\odot 2011$ S. Karger AG, Basel

\section{Introduction}

Singapore, a small, highly urbanized and cosmopolitan city-state nestled in South East Asia, faces a rapidly graying population like many other countries in Asia. Currently, approximately $8.5 \%$ of the population comprises older persons aged $\geq 65$ years and by the year 2030 , it is estimated to reach $18.9 \%$ [1]. Accompanying the rapid ageing of the population is an anticipated more than doubling of the number of persons with dementia (PWD) from 22,000 to 53,700 by $2020[2,3]$. Hence, quality care for PWD and their family caregivers is fast becoming an important issue for the country.

Amongst many issues germane to dementia care, management of the behavioral and psychological symptoms of dementia (BPSD) ranks foremost. These disruptive and challenging behaviors undermine quality of life in PWD and exert a tremendous burden, both emotionally and financially, on their caregivers $[4,5]$.

\section{KARGER}

Fax +4161306 1234

E-Mail karger@karger.ch

www.karger.com
(C) 2011 S. Karger AG, Basel

$1420-8008 / 10 / 0306-0540 \$ 26.00 / 0$

Accessible online at:

www.karger.com/dem 
Nonpharmacological therapies (NPT), such as music therapy and structured activity programs, are varied and multifaceted interventions that have shown promise in eliciting broad ranges of beneficial effects in PWD [6]. However, NPT are often not adequately implemented, and evidence abounds on the widespread use of antipsychotics despite their serious side effects $[4,7]$. Numerous dementia practice guidelines similarly advocate nonpharmacological measures as first-line therapy for BPSD $[2,8,9]$ and antipsychotics only as a last recourse. Clearly, more research to provide evidence-based practice in the use of NPT for BPSD is necessary and its wider application even more pressing.

As for the nature and conduct of NPT, multimodal approaches based on a combination of individualized interdisciplinary and holistic treatment have been advocated [10]. NPT can be implemented in a structured activity program led by trained personnel. Occupational therapists, by nature of their professional goals and training, often take the lead in the design and conduct of such programs in our country. Occupational therapy aims to improve patients' ability to perform activities of daily living, and promote independence and participation in social activities [11]. Occupational therapists often use structured activity programs to impact clients' occupational performance and quality of life. A critical review of 19 studies by Law et al. [12] on the effectiveness of activity programs for older PWD showed that several studies documented improvements in the well-being, communication, mental status and emotional state of PWD.

In addition, music therapy has shown promise as a NPT for BPSD [13]. Elderly nursing home residents with dementia were found to have significantly less episodes of screaming when exposed to music [14], while a more recent case-control study found a significant reduction in activity disturbance, aggressiveness and anxiety scores of the Behavior Pathology in Alzheimer's Disease Rating Scale (BEHAVE-AD) in the music intervention group [15]. Music therapy protocols have been shown to facilitate active participation even in advanced stages of dementia, with alert responses, increased social engagement and participation in physical exercise routines [16].

Combined music therapy- and occupational therapybased activity programs have been demonstrated to maintain occupational performance and quality of life, as well as decrease disruptive and depressive behaviors [17] in PWD. However, the frequency and intensity of these programs vary, and it has not been explored if a weekly program in an ambulatory out-patient setting would have similar benefits.

Music Therapy and Structured Activity for PWD
As Singapore is not a welfare state, patients have to pay out of their own pockets for healthcare services, with subsidies available only after stringent financial means testing. Day activity programs are resource heavy in terms of manpower and time, resulting in high costs and charges for clients. Hence, clients may be less willing to utilize them or only make use of them infrequently. For this reason, it is pertinent to investigate if a less intensive, oncea-week music therapy and activity-based program can ameliorate behavioral and depressive symptoms in PWD, with its attendant benefit on caregiver burden. This forms the aim of the study.

\section{Methods}

\section{Subjects/Participants}

The subjects were recruited in a naturalistic setting of an outpatient dementia clinic of a tertiary hospital, Alexandra Hospital, in Singapore. The subjects had been diagnosed with Alzheimer's disease or vascular dementia by geriatricians using DSM-IV criteria [18] and were receiving medical treatment and follow-up in the clinic. Ethics approval for the study was received from the Domain Specific Review Board of the National Healthcare Group of Singapore. Informed consent was obtained from the family caregiver or a legally acceptable representative where appropriate.

Subjects who satisfied inclusion criteria for the intervention were placed in the program on a first-come first-serve basis. Inclusion criteria comprised subjects with moderate dementia with a Mini-Mental State Examination (MMSE) score of 10-20, Functional Assessment Staging Tool ratings [19] stages 5-6, having a reliable caregiver who stayed with the subject and spent at least $4 \mathrm{~h}$ a day with him/her, no hospitalizations in the previous 3 months and physically able to participate in activities for at least half a day. Subjects who suffered from advanced cardiovascular, pulmonary disease or cancer were excluded. Those who had acute medical problems such as fever, pain and delirium or exhibited overtly disruptive behaviors such as shouting, screaming and physical aggression were also excluded. Patients on psychotropic medications had to be on a stable dose for at least 3 months prior to the intervention. As the intervention was carried out only once a week with capacity limited to 8 persons per session, some subjects were first put on a wait-list pending availability in subsequent runs of the program. Figure 1 depicts the procedure adopted for the study.

\section{Outcome Measures}

Biodemographic and clinical data, such as the MMSE and use of psychotropic medications, were obtained from the subjects' case records. The Revised Memory and Behavioral Problems Checklist (RMBPC) [20] and the Apparent Emotion Scale (AES) [21] were used to measure changes in the primary outcomes of mood and disruptive behavior. These scales were administered to the family caregivers at baseline and 8 weeks later in both the intervention and wait-list groups.

The RMBPC [20] was used to assess the frequency of problem behaviors in dementia and its impact on the caregiver in the pre- 
vious week. It was completed by the caregiver and consisted of 24 items scored on a scale of $0-4$. The subscales within pertained to memory, disruptive behaviors and depression, and each had a respective subscale score. Scores for each domain were calculated as the product of the frequency and caregiver reaction scores. The subscale scores were summed to give a total score, with higher scores denoting more severe behavioral problems.

The modified AES, derived from the original Lawton Observed Emotion Rating Scale, was used to measure 6 types of affect in the PWD: pleasure, anger, anxiety, depression, interest/ motivation and contentment. Responses were elicited from the caregiver on how often the PWD expressed a particular emotion in the previous 2 weeks using a Likert scale from 1, denoting 'never', to 5, denoting 'several times a day'. The negative emotions (anger, anxiety and depression) were reverse scored. A summed score was calculated, with higher scores denoting a more positive affect.

\section{Statistics}

Baseline demographic and clinical characteristics between the control and intervention group subjects were compared with independent samples $t$ tests. Post-intervention differences in the main outcome measures, AES and RMBPC, between the 2 groups were analyzed, as was the difference in the mean scores before and after intervention. The sample size was estimated from the results of an earlier pilot study [22], and yielded a sample size of 50 subjects for $80 \%$ power. All statistical analysis was performed with the Statistical Package for the Social Sciences (SPSS) version 18.0.

\section{Intervention}

The music therapy and activities program (MAP) is an ongoing program in the center for persons with moderate stage dementia. The participants come once a week for 8 consecutive weeks to receive $6 \mathrm{~h}$ of structured activities in a group with no more than 8 persons in each session. The sessions are conducted by 2 occupational therapists, a certified music and licensed creative arts therapist and a registered nurse. Family caregivers are strongly encouraged to join in the program, although it is not compulsory for them to do so. The aims of the program are to provide a structured day routine, encourage physical exercise and cognitive stimulation, explore capabilities and interests, and facilitate sharing and interaction in PWD. The therapists also schedule regular meetings and feedback sessions with the family caregivers to better understand the PWD, reflect on his/ her progress and provide ideas and recommend strategies on caregiving where appropriate. On the final session, a summary meeting is held with the caregivers to conclude the 8 weeks program.

For this particular study, the interventions were carried out over 8 weeks with the therapists assessing the subjects with respect to understanding their cognitive and functional status, past interests and hobbies, personalities and biographies, as well as the family structure and dynamics at the beginning of the program. A typical session began in the morning with warming up and stretching exercises, followed by a leisurely group walk in a setting close to nature. This was followed by the day's 'highlight' activity, which varied over the 8 weeks from gardening and horticulture to massage in combination with aromatherapy, interaction with animals and pets, intergenerational activities with preschool children, and organized outings to places of local heritage.

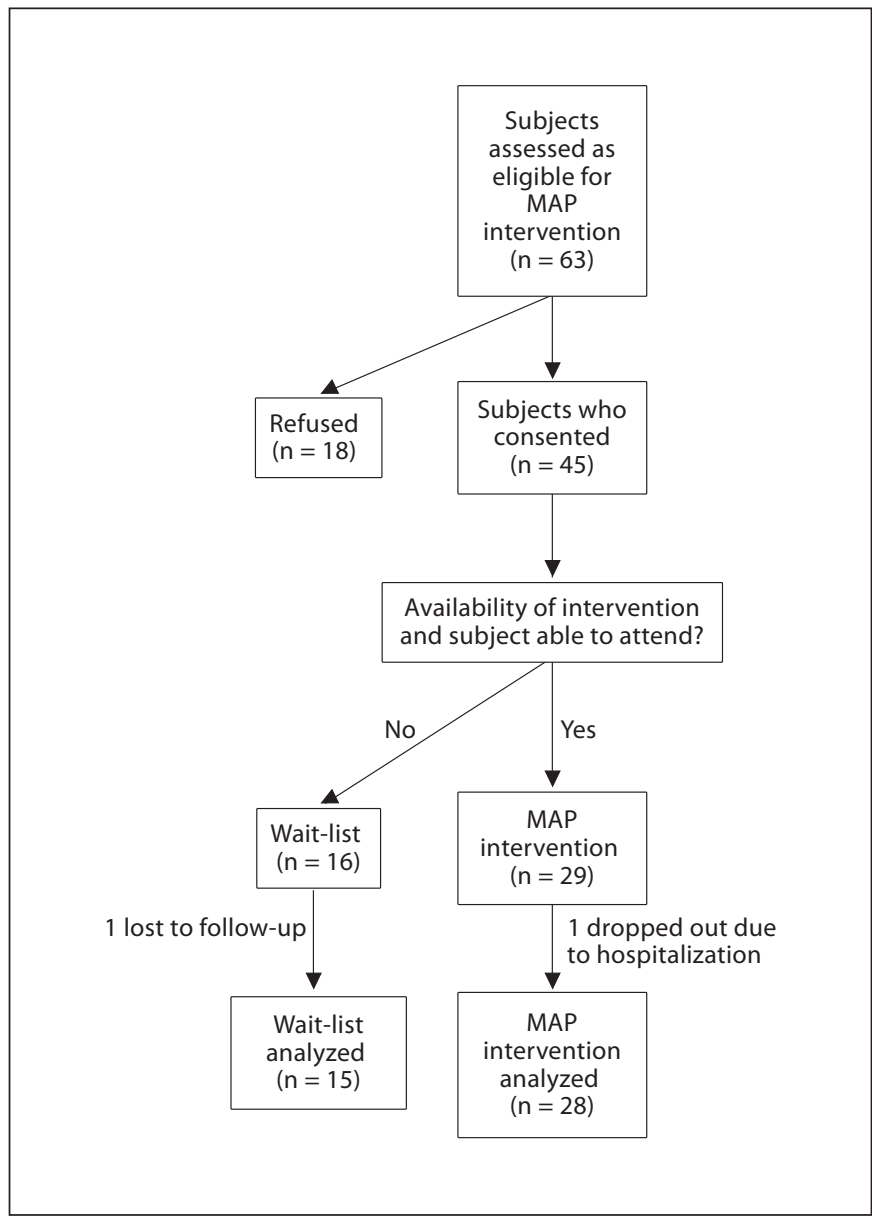

Fig. 1. Flow diagram for study procedure.

After a lunch break, the music therapist facilitated various music activities for the group, based on the needs and preferences of the subjects. Activities included singing, music and movement, and memory sequences accompanied by music as well as drumming. The subjects were also motivated to explore playing different instruments, dancing with scarves or engaging in other structured tasks with singing or music (live or recorded) in the background.

The afternoon activities were conducted in smaller groups or on a one-to-one basis as the need dictated. Reminiscence or cognitive games such as bingo and money handling were the more common activities carried out. The day's session typically ended with care staff meeting the caregivers for a short debriefing and feedback session.

The control group subjects did not attend this intervention program, but continued to receive usual care by their respective physicians in the dementia clinic. None of the subjects in either group attended any other day activity program outside our center. Use of psychotropic medications was permitted during the 8-week study period, but adjustment in the medications was discouraged. If the subject needed adjustment in psychotropics, he had to be excluded from the final data analysis. 
Table 1. Baseline characteristics

\begin{tabular}{|c|c|c|c|}
\hline & $\begin{array}{l}\text { Control group } \\
(\mathrm{n}=15)[\mathrm{SD}]\end{array}$ & $\begin{array}{l}\text { Intervention group } \\
(\mathrm{n}=28)[\mathrm{SD}]\end{array}$ & $\mathrm{p}$ \\
\hline Mean age, years & $78.5[9.1]$ & $78.1[7.2]$ & 0.116 \\
\hline \multicolumn{4}{|l|}{ Gender } \\
\hline Male & $5(33.3 \%)$ & $7(25 \%)$ & \multirow[t]{2}{*}{0.65} \\
\hline Female & $10(66.7 \%)$ & $21(75 \%)$ & \\
\hline \multirow{3}{*}{$\begin{array}{l}\text { Mean MMSE score } \\
\text { Use of psychotropic } \\
\text { medications }\end{array}$} & $14.1[7.1]$ & $14.5[6.3]$ & 0.857 \\
\hline & & & \\
\hline & $4(25 \%)$ & $6(22.2 \%)$ & 0.835 \\
\hline
\end{tabular}

Table 2. AES and RMBPC scores before and after MAP intervention

\begin{tabular}{|c|c|c|c|c|c|c|c|}
\hline \multirow{2}{*}{$\begin{array}{l}\text { Outcome } \\
\text { measures }\end{array}$} & \multicolumn{3}{|c|}{ Before intervention } & \multicolumn{4}{|c|}{ After intervention } \\
\hline & $\begin{array}{l}\text { control } \\
\text { group (SD) }\end{array}$ & $\begin{array}{l}\text { intervention } \\
\text { group (SD) }\end{array}$ & $\begin{array}{l}\mathrm{p} \text { value } \\
(95 \% \mathrm{CI})\end{array}$ & $\begin{array}{l}\text { control } \\
\text { group (SD) }\end{array}$ & $\begin{array}{l}\text { intervention } \\
\text { group (SD) }\end{array}$ & $\begin{array}{l}\mathrm{p} \text { value } \\
(95 \% \mathrm{CI})\end{array}$ & $\begin{array}{l}\mathrm{p} \text { value ( } 95 \% \text { CI of the } \\
\text { mean score difference) }\end{array}$ \\
\hline \multicolumn{8}{|l|}{ AES } \\
\hline Total score & $17.1(4.3)$ & $18.2(6.4)$ & $0.118(-2.6$ to 4.9$)$ & $16.6(5.1)$ & $19.0(4.8)$ & $0.159(-1.01$ to 5.92$)$ & $0.479(-1.0$ to 5.9$)$ \\
\hline \multicolumn{8}{|l|}{ RMBPC } \\
\hline Total score & $62.3(60.2)$ & $75.3(47.6)$ & $0.625(-21.5$ to 47.4$)$ & $78.6(75.7)$ & $54.5(40.1)$ & $0.205(-62.1$ to 13.8$)$ & $0.006(-62.17$ to -11.20$)$ \\
\hline Memory & $39.3(38.3)$ & $35.5(28.1)$ & $0.060(-24.8$ to 17.4$)$ & $42.2(31.9)$ & $31.1(24.4)$ & $0.245(-30.0$ to 7.9$)$ & $0.374(-28.53$ to 5.00$)$ \\
\hline Disruptive behavior & $10.7(17.5)$ & $19.4(18.3)$ & $0.453(-3.1$ to 20.5$)$ & $14.7(23.4)$ & $14.8(20.8)$ & $0.989(-15.2$ to 15.4$)$ & $0.707(-11.06$ to 3.82$)$ \\
\hline Depression & $13.1(21.0)$ & $20.5(23.5)$ & $0.030(-7.4$ to 22.3$)$ & $24.6(34.7)$ & $11.7(15.9)$ & $0.121(-29.44$ to 3.58$)$ & $0.019(-35.6$ to -9.7$)$ \\
\hline
\end{tabular}

\section{Results}

Over a period of 8 months, 63 subjects were assessed to be eligible for the intervention and 45 agreed to participate (fig. 1). One subject in the intervention group dropped out as he had to be admitted to the hospital for treatment of pneumonia, while another subject in the control group was lost to follow-up.

Twenty-eight subjects with moderate stage dementia completed the MAP intervention, while 15 others, who were on the wait list for the program and had yet to receive any intervention, served as the control group.

\section{Subject Characteristics}

As seen in table 1, there were no significant differences in the baseline characteristics of the intervention and control group subjects. Mean MMSE score of the 2 groups was also comparable at 14.5 and 14.1, respectively, and there was no difference in the number of subjects on psychotropic drugs.

\section{Efficacy of Intervention}

Baseline AES and RMBPC scores were not significantly different between the intervention and control groups (table 2), except for the depression subscale of RMBPC which was higher in the control group. After intervention, RMBPC scores improved significantly $(p=0.006)$ with 95\% CI of the difference between the mean intervention and control group scores compared to baseline at -62.1 to -11.20 . Total RMBPC scores decreased in the intervention group from 75.3 to 54.5 , but worsened in the control group, increasing from 62.3 to 78.6. The improvement in RMBPC scores were mediated primarily through improvement in the depression subscale of the RMBPC which improved from 20.5 to 11.7 in the intervention group and worsened from 13.1 to 24.6 in the control group. The RMBPC items that showed the greatest improvement were 'talking about feeling lonely', followed by 'comments about feeling worthless or being a burden to others' and 'appears sad or depressed'.

\section{Discussion}

The results of our study show that a weekly session of music and activity-based programming over 8 weeks resulted in significant improvements of behavioral and depressive symptoms in PWD reported by their caregivers. 
Subdomain analysis of the RMBPC revealed that this benefit was brought about primarily through clear improvements in the mood domain, although there was also a nonsignificant improvement in the disruptive behavior subscale scores. The scores for the memory domain remained largely unchanged after intervention. As for the AES scores, although the change after intervention did not achieve significance, there was a trend towards improvement.

The positive results of our study support the findings of other studies that showed the benefits of cognitively stimulating activities and music therapy interventions in PWD [23, 24]. However, the interesting aspect of this study lies in the benefits of an intervention that is relatively modest in intensity with $6 \mathrm{~h}$ of structured programming just once a week. It would thus be pertinent to explore what might really have made an impact in the PWD and how this change could have been effected.

The subjects in this study comprised mainly persons with moderate stage dementia. At this stage, with the loss of executive control, most PWD lose the ability to plan and form an agenda in daily life. Given the trend towards dual-income homes in Singapore, many working adults leave the care of the PWD to foreign domestic maids. Most of these maids do not speak the vernacular of the PWD, thus communication and meaningful interaction can be at best modest. For this reason, our subjects could have led relatively trite lives with little activity or engagement in their homes. Intervention through the program to provide structure, stimulation and regular engagement with the therapist and other participants may be a possible reason for the positive effects of the intervention. However, the content of the intervention, namely meaningful activities and music therapy, can also account for the positive results.

Havinghurst's activity theory [25] posits that older adults like to connect to others and participate in activities. Persons who are withdrawn have been found to have less psychological and physical well-being when compared to those who are more active [24]. This idea has influenced dementia care where healthcare professionals and researchers have emphasized the use of meaningful activities with PWD [26]. PWD would still want to continue to participate in meaningful activities to maintain connection, belonging, autonomy and their sense of selfidentity even as the disease progresses $[10,27,28]$. PWD who are not involved in meaningful activities for long periods of time may experience increased psychiatric or behavioral symptoms such as anxiety, depression and paranoia, while activities promote feelings of purpose and accomplishment, and positively impact negative emotions [28]. In Kitwood's model of needs [29], purposeful occupation is mentioned as an essential element that satisfies the emotional needs of PWD. The employment of occupational therapists in this intervention to better understand the subjects through assessments that involve family members is key to being able to provide meaningful activities tailored to the individual needs of the PWD.

Music therapy has been found to facilitate active participation even very late in dementia $[16,30]$. A possible hypothesis is that the amygdala, one of the last parts of the brain to be affected by dementia, still receives, reacts to and expresses mood and emotion in PWD. Therefore, music as a therapeutic intervention needs to target the person's ability to attend to the process and respond with emotion [28]. Holmes et al. [31] demonstrated that live interactive music encouraged immediate and positive engagement in PWD with apathy when compared to passive prerecorded music or no music. Similarly, music that entails active engagement with the PWD in the form of dancing or movement, rhythmic exercise or singing has yielded promising results [32, 33]. Familiar songs and melodies may trigger memories and lead to increased sharing and interaction with others.

The music therapy intervention utilized the live music, person-centered engagement approach whereby participants were actively assisted by the therapist to participate within a group setting in singing, rhythmic drumming, vocal or percussion improvisation, dancing and movement. A positive social effect was noted in those who were initially reluctant. These participants were often seen smiling or presented with increased energy during music sessions over the course of the program. They appeared to be motivated by the live music, familiar songs of their era, varied music activities and interaction with the therapist and their peers. Participants were invited to listen first, and then to participate as they felt more comfortable over time. Our experience complements the opinion that structured music and meaningful activities offer opportunities for social interaction and connectedness, to develop new hobbies, to appreciate and embrace new aspects of one's culture, and to boost one's physical and cognitive functioning [34].

These encouraging results have important implications in our country where patients have to pay for healthcare services. Although there are government subsidies and long-term health insurance available, these are still largely focused on tertiary episodic hospital care with little provision for outpatient community-based services 
such as day care or structured activity programs for seniors. Statistics show a heavy reliance on foreign domestic maids, with 1 being employed in every 6 households in Singapore to handle household chores and caregiving for the young and old [35]. Many PWD are being taken care of by foreign domestic maids in their own homes. While the maids may be able to ensure safety and physical care, the cultural and language barriers limit their ability to effectively engage with the person they are caring for. The study's findings that a weekly MAP can improve disruptive behaviors and depressive symptoms in PWD will be much welcomed as the extra cost incurred with a once a week session is considerably less than a more intensive intervention. Family caregivers now have an extra care option that is modest in cost to consider, beyond medication, and which holds the potential to improve the quality of life both for the PWD and the caregiver as well.

There are, however, some limitations to consider in this study. First, a plausible reason for the nonsignificant results of the AES could lie in the properties of the scale. The original AES scale was designed to be a direct observation measure, while the modified version used in this study relies on recall of specific emotions displayed. The repeat administration of the AES only at the end of the intervention could have resulted in problems with accurate recall on the part of the caregiver with regard to the emotions displayed by the PWD, especially during the time the intervention was carried out.

Second, the small sample size, nonrandomized and nonblinded nature of the study limits the validity of the results. Consent was obtained primarily from the family caregivers and only caregivers who agreed to recruit the PWD into the intervention were included in the study. This naturally introduces a response bias in the sample. We did not compare the characteristics of caregivers who consented with those who did not. There are possible inherent differences in these 2 groups that may impact the outcomes of the study. Compared to those who refused the intervention, it is likely that caregivers who consented comprised those who recognized the value of music and structured activity, and who were able and willing to take time to bring the PWD for the intervention each week. The willingness of the PWD to attend the program could have also selected a study sample that was probably more inclined to music and group social activities. Given this more selected sample of patient caregiver dyad, there may be a limitation to generalizing the results of the study to the population at large.

Finally, the intervention was carried out by occupational and music therapists with much interest, expertise and experience in dementia care. We acknowledge that professionals with these skills are not widely available, hence the reproducibility of these positive results in other settings may be limited.

Nonetheless, much value of this study lies in its naturalistic setting. In practice, patients are offered interventions that are deemed suitable for them, but they ultimately make the choice based on their discretion and preferences. Satisfying study inclusion criteria is akin to determining the suitability of the patient for the intervention, while consent for the study likens the patient's acceptance of the clinician's recommendation in the clinical setting. The use of the wait-list group of patients as a control is reasonable as the wait-list comprised only patients who had agreed to the intervention, thereby controlling for inherent patient and caregivers differences with regard to their attitudes and beliefs towards the intervention. Finally, the similar baseline characteristics of the intervention and wait-list control groups and the positive results of the intervention despite the small sample size lend much credence to the validity of the results.

\section{Conclusion}

A weekly session of live music therapy- and occupational therapy-based structured activities over 8 weeks resulted in improvements in disruptive behaviors and depressive symptoms in PWD. This has important implications for clinicians, PWD and their family caregivers, especially given the relatively small benefits of antidementia drugs and important side effects of antipsychotics in the management of behavioral problems, not to mention the paucity of benefits of drug treatment on quality of life in PWD to date. As a weekly intervention is modest in cost and holds the potential to improve quality of lives of both PWD and their caregivers, it is hoped that the positive findings of this study will broaden the care options available for PWD and provide the impetus for further research on music- and activity-based interventions to address issues of efficacy, quality of life and cost-effectiveness in PWD and their caregivers. 


\section{References}

1 Ministry of Community Development, Youth and Sports: Singapore social statistics in brief 2008. http://www.mcys.gov.sg/ MCDSFiles/download/social\%20stats $\% 20$ 2008.pdf (accessed May 8, 2008).

2 Singapore Ministry of Health. MOH Clinical Guidelines 5/2001: Dementia. Singapore, Singapore Ministry of Health, 2007.

3 Asia Pacific Members of Alzheimer's Disease International. Dementia in the Asia Pacific Region: The epidemic is here. Alzheimer's Disease International 2006. http://www.alz. co.uk/research/files/apreport.pdf.

-4 Swanson KA, Carnahan RM: Dementia and comorbidities: an overview of diagnosis and management. J Pharm Pract 2007;20:296317.

5 Cohen-Mansfield J: Theoretical Frameworks for Behavioral Problems in Dementia. Alzheimers Care Q 2000;1:8-21.

6 Cohen-Mansfield J: Nonpharmacologic interventions for inappropriate behaviors in dementia: a review, summary and critique. Focus 2004;2:288-308.

7 Banerjee S: The use of antipsychotic medication for people with dementia: time for action. http://www.dh.gov.uk/prod_consum_ $\mathrm{dh} /$ groups/dh_digitalassets/documents/ digitalasset/dh_108302.pdf. 2009.

8 Burns A, Iliffe S: Dementia. BMJ 2009;338: 405-409.

9 The British Psychological Society and The Royal College of Psychiatrists. A NICESCIE guideline on supporting people with dementia and their carers in health and social care. http://www.nice.org.uk/nicemedia/live/10998/30320/30320.pdf. 2007.

10 Allen B: Multimodal behavior management for people with dementia. Am J Alzheimers Dis Other Demen 2002;17:2:89-91.

-11 Graff MJL, Adang EMM, Vernooii-Dassen MJM, Dekker J, Jönsson L, Thijssen M, Hoefnagels WHL, Rikkert MGM: Community occupational therapy for older patients with dementia and their caregivers: cost effectiveness study. BMJ 2008;336:134-138.

12 Law M, Stewart D, Letts L, Pollock N, Bosch J, Philpot A, Westmorland M: Effectiveness of activity programmes for older persons with dementia. http://fhs.mcmaster.ca/rehab/ebp/pdf/activity.pdf.
13 Doody RS, Stevens JC, Beck RN, et al: Practice parameter: management of dementia (an evidence-based review). Report of the Quality Standards Subcommittee of the American Academy of Neurology. Neurology 2001 56:1154-1166.

14 Cohen-Mansfield J, Werner P, Marx MS: Screaming in nursing home residents. J Am Geriatr Soc 1990;36:785-792.

15 Svansdottir H, Snaedal J: Music therapy in moderate and severe dementia of Alzheimer's type: a case-control study. Int Psychogeriatr 2006;18:613-621.

16 Clair AA, Matthews RM, Kosloski K: Assessment of active music participation as an indication of subsequent music making engagement for persons with midstage dementia. Am J Alzheimers Dis Other Demen 2005;20:37-40.

17 Douglas S, James I, Ballard C: Non-pharmacological interventions in dementia. Adv Psychiatr Treat 2004;10:171-179.

18 American Psychiatric Association. Diagnostic and Statistical Manual of Mental Disorders (DSM-IV). American Psychiatric Association, Washington, 1994.

19 Reisberg B: Functional assessment staging (FAST). Psychopharmacol Bull 1988;24 653-659.

20 Teri L, Truax P, Logsdon R: Assessment of behavioral problems in dementia: The Revised Memory and Behavior Problems Checklist. Psychol Aging 1992;7:622-631.

21 Lawton MP, Van Haitsma K, Perkinson M Observed affect and quality of life in dementia: further affirmations and problems. J Mental Health Aging 1992;69-81.

22 GZ Lee, M Kwan, D Chen, HL Chionh, J Goh, P Yap: A pilot study on the effects of a music therapy cum activity based programme on behavioural and depressive symptoms in dementia. Ann Acad Med Spore 2008;37:S79.

23 Brotons M, Koger SM, Pickett-Cooper PK: Music and dementias: a review of the literature. J Music Ther 1997;34:204-245.
24 Sung H, Chang A, Abbey J: The effects of preferred music on agitation of older people with dementia in Taiwan. Int J Geriatr Psychiatry 2006;21:999-1000.

25 Phinney A, Chaudhury H, O’Connor DL: Doing as much as I can do: the meaning of activity for people with dementia. Aging Mental Health 2007;11:384-393.

26 Nolan M, Ryan T, Enderby P, Reid D: Towards a more inclusive vision of dementia care practice and research. Dementia 2002;1: 193-211.

27 Vernooij-Dassen M: Meaningful activities for people with dementia. Aging Ment Health 2007;11:359-360.

28 Zeisel J, Raia P: Non-pharmacological treatment for Alzheimer's disease: a mind-brain approach. Am J Alzheimers Dis Other Demen 2000;15:331-340.

29 Kitwood TM: Dementia Reconsidered: The Person Comes First. Buckingham, Open University Press, 1997.

30 Eggermont LH, Scherder EJ: Physical activity and behaviour in dementia: a review of the literature and implications for psychosocial intervention in primary care. Dementia 2006:5:411-428

- 31 Holmes C, Knights A, Dean C, Hodkinson S, Hopkins V: Keep music live: music and the alleviation of apathy in dementia subjects. Int Psychogeriatr 2006;18:623-630.

-32 Hanson N, Gfeller K, Woodworth G, Swanson E, Gerand L: A comparison of the effectiveness of differing types and difficulty of music activities in programming for older adults with Alzheimer's disease and related disorders. J Music Ther 1996;33:93-123.

33 Mathews RM, Clair AA, Kosloski K: Keeping the beat: use of rhythmic music during exercise activities for the elderly with dementia. Am J Alzheimers Dis Other Demen 2001;16: 377-380.

34 Ybarra O, Burnstein E, Winkielman P, et al: Mental exercising through simple socializing: social interaction promotes general cognitive functioning. Pers Soc Psychol Bull 2008;34:248-259.

35 Ministry of Manpower: Your guide to employing a foreign domestic worker. http:// www.mom.gov.sg/publish/etc/medialib/ mom_library/work_pass/files2.Par.80861. File.tmp/FDW\%20EG(Eng)\%20Std.pdf. 2008. 